\title{
Dos supuestos reales sobre el funcionamiento de los órganos de un Ayuntamiento
}

\author{
José Mario Corella Monedero \\ Abogado. Secretario General (jubilado). \\ Ayuntamiento de Madrid. \\ Ex Director General de Administración Local
}

SUMARIO: I. VALOR DE LAS PROPUESTAS ADOPTADAS EN UNA MISMA SESIÓN Y CON POSIBLE CONTRADICCIÓN ENTRE ELLAS, A INICIATIVA DE GRUPOS MUNICIPALES DISTINTOS. II. VALOR DE LOS DICTÁMENES EMITIDOS POR LAS COMISIONES INFORMATIVAS EN EXPEDIENTES EN LOS QUE SE HAN OMITIDO TRÁMITES ESENCIALES.

Cuando acepto la invitación para participar en el número monográfico de la Revista de Estudios de Administración Local en honor del Profesor Martín-Retortillo, se me plantea la duda entre hacer un estudio teórico de cualquier tema relacionado con la Administración Local o recoger, con las modificaciones nacidas de un análisis más ponderado que pueden ofrecer la tranquilidad del despacho y la distancia en el tiempo, informes realizados sobre el funcionamiento municipal en mi paso, como Secretario General por el Ayuntamiento de Madrid.

Pienso que a él le gustaría más esto último porque, al fin y a la postre, él enseñaba para que pudiésemos andar entre las difíciles arenas movedizas de las normas administrativas.

Dificultad que no es nueva en nuestra vida jurídica, justificada hoy por el poder expansivo de la administración y la «necesaria» tendencia a regular todos los aspectos, hasta los más nimios, de la vida social.

Ya, en el siglo XVIII, Mora y JARABA [Tratado crítico. Los errores del Derecho civil y los abusos de los jurisperitos, para utilidad pública, Madrid, 1748 (citado por F. DE CASTRO en Derecho civil de España, 2. ${ }^{\circ}$ ed. Madrid, 1949)] decía «Miserables una, dos y tres veces los juristas que estamos sumergidos entre escollos de disposiciones invencibles», y GoroSABEL también afirmaba que «La legislación española es un océano intransitable aun para el náutico más estudioso que se ocupara en pasarlos»; si Quiroga Porras, en 1836 hace la cuenta de los distintos cuerpos legales aplicables y suma 13.627 leyes (Compendio histórico del Derecho civil de España, Santiago, 1836, cita también de F. DE CASTRO, ob. cit.), ¿qué pensarían todos ellos de la situación actual y cuantas normas sumarían? 
Pues bien, entre esas arenas o esas olas hay que desenvolverse y lo que sigue es muestra de ese desenvolvimiento, con las urgencias que en cada caso fueron exigidas.

En todo caso el hilo conductor es el de tratarse de informes sobre situaciones que afectan al funcionamiento municipal y la validez de los acuerdos.

\section{VALOR DE LAS PROPUESTAS ADOPTADAS EN UNA MISMA SESIÓN Y CON POSIBLE CONTRADICCIÓN ENTRE ELLAS, A INICIATIVA DE GRUPOS MUNICIPALES DISTINTOS}

1. En la sesión plenaria de ... que, con carácter de extraordinaria, se convocó a instancia del Grupo municipal ... sobre «situación de la Empresa Mixta X», fueron presentadas diversas propuestas por los Grupos municipales resultando todas ellas aprobadas en los términos que del acta se deducen.

Como quiera que las propuestas de los Grupos de oposición se aprobaron con la abstención del Equipo de Gobierno, se planteó en la propia sesión la validez de los acuerdos que podrían resultar contradictorios con otros adoptados previamente, a propuesta del Equipo de Gobierno, y se solicitó en ese momento informe de la Secretaría General a ese respecto.

2. (Las propuestas aprobadas y el resultado de la votación se enumeran en el informe pero no afectan al contenido jurídico de éste, por lo que no se transcriben).

3. Un primer punto a plantear es el del carácter del Pleno en que tales propuestas y votaciones se producen, así como lo que, de entre lo acordado, no coincida con el Orden del Día fijado por el Presidente en la convocatoria de la sesión.

El Pleno de ... fue extraordinario, convocado a solicitud de más de la cuarta parte del número de Concejales (arts. 46.2.a L.R.B.R.L., 48.1 T.R.R.L. y 78.2 R.O.F.) en cuya virtud y de acuerdo con el artículo 78.2 R.O.F., se especificaba el enunciado del Orden del Día que solamente en parte fue aceptado por el Sr. Alcalde en su Decreto de Convocatoria, razonando, como indica el citado artículo del R.O.F., el porqué de la exclusión de parte del enunciado. Entendía el Sr. Alcalde que el contenido final de la solicitud de los Concejales firmantes de la petición de sesión «no es mate- 
ria de la competencia del Ayuntamiento Pleno, sino de los correspondientes órganos de la Sociedad».

Como consecuencia de ello el Orden del Día se cursó con el siguiente enunciado: «Análisis de la situación actual de la Empresa Mixta X», no apareciendo en tal enunciado nada que hiciera referencia a la «toma de decisiones que garanticen su viabilidad, los puestos de trabajo existentes y la calidad de los servicios que se presten a los madrileños».

Tiene, a juicio del informante, interés esta distinción porque, de conformidad con lo preceptuado en el artículo 51 T.R.R.L. y 83 R.O.F., «serán nulos los acuerdos adoptados en sesiones extraordinarias sobre asuntos no comprendidos en su Convocatoria» y es claro que la toma de decisiones acerca de la viabilidad, garantía de los puestos de trabajo y mantenimiento de la calidad de los servicios no eran asuntos comprendidos en la Convocatoria (que solamente hablaba de análisis) porque expresamente el $\mathrm{Sr}$. Alcalde había puesto de manifiesto su criterio en orden a la incompetencia orgánica del Pleno del Ayuntamiento en estas materias.

Así, únicamente con el carácter de recomendaciones al Equipo de Gobierno, avaladas o apoyadas por los Grupos Políticos municipales que en cada caso las votaron, las proposiciones podrían admitirse como resultado del análisis.

El Equipo de Gobierno a partir de tales recomendaciones deberá llevar a cabo las acciones concretas que procedan para someter al Pleno las decisiones que procedan en orden al servicio que presta la Empresa.

Consecuentemente, parece que todas las recomendaciones (el Orden del Día sólo decía análisis) adoptadas en la sesión o, al menos, las referidas a materia excluidas de la Convocatoria, no podrían ser consideradas como acuerdos pues en tal caso serían anulables por incurrir en una infracción del ordenamiento jurídico (art. 48.1 L.P.A. - hoy sería el art. 63 L.R.J.P.A.C.-) que se da respecto a los artículos antes citados, 51.d del T.R.R.L. y 83 del R.O.F.

4. En virtud de lo anteriormente expuesto, el Equipo de Gobierno deberá, en la línea de las recomendaciones adoptadas, iniciar los correspondientes expedientes tramitándolos por la vía normal o de urgencia según proceda, sometiendo la resolución de los mismos a los órganos competentes, debiendo, además, llevar a cabo las gestiones que, no dependiendo en su resolución de la Corporación, deba practicar con Entidades de crédito y compañías aseguradoras. 
El precedente informe es conocido por el Pleno del Ayuntamiento en sesión celebrada dos meses después en la cual, como ampliación o aclaración de él, a instancia de la Presidencia, verbalmente como Secretario General, expuse lo siguiente (se copia literalmente del Acta de la sesión):

«...los criterios contenidos en mi informe, en relación con la sesión... (el transcrito más arriba), son exactamente los mismos que ha venido manteniendo esta Secretaría desde la publicación del Reglamento de Organización, Funcionamiento y Régimen Jurídico de las Corporaciones Locales. Los mismos que se mantuvieron en un informe de 4 de diciembre de 1987, emitido como consecuencia de la petición del entonces Primer Teniente de Alcalde» que solicitó al Secretario General que diferenciara jurídica y prácticamente las Proposiciones, las Mociones de Urgencia y los Ruegos y Preguntas.

«En este sentido se emitió entonces informe en el que, por no ser excesivamente largo, en lo que hacía referencia a las proposiciones se decía lo siguiente: las Proposiciones, también las Mociones, tienen un carácter extraordinario, puesto que, en principio, sólo pueden incluirse en el Orden del Día aquellos asuntos que hayan sido previamente dictaminados. Solamente pueden incluirse asuntos no dictaminados a través de las Proposiciones por razones de urgencia debidamente motivadas debiéndose, por tanto, acreditar por el proponente esa circunstancia, correspondiendo a la Alcaldía Presidencia determinar si se da o no la misma, sin perjuicio de su ratificación por el Pleno, por mayoría simple. Y ello es así porque conforme al artículo 123.1 del R.O.F., a las Comisiones Informativas les corresponde el estudio, informe o consulta de todos los asuntos que hayan de someterse al Pleno, sin excepción alguna, salvo los urgentes. Si la proposición es la propuesta que, por razones de urgencia, se incluye en el Orden del Día, sobre un asunto que no ha podido ser dictaminado previamente por la Comisión Informativa respectiva, comporta una excepción a la regla general que es que quienes pretendan obtener del Pleno Corporativo un acuerdo respecto de la materia objeto de su competencia, utilicen la vía ordinaria que permite el dictamen previo de la Comisión, antes de su consideración por dicho órgano colegiado.

«Y dicha vía ordinaria no es otra que la iniciación de un expediente por quienes ostentan la facultad de dirigir y gestionar los Servicios municipales, esto es, por el Presidente de la Corporación en cuanto que a él le corresponde, conforme al art. 21.1.a) de la L.R.B.R.L., el gobierno y la administración municipal, y por los Concejales Delegados de Área por delegación de aquél. Por tanto la proposición, de no existir la urgencia, se ha de convertir en una petición del Concejal que la formule, que obviamente será de la oposición (el Equipo de Gobierno y el Alcalde lo pueden iniciar de oficio directamente) dirigida al Alcalde o Delegado de Área que tenga atribuida la competencia en materia objeto de la misma, con el fin de que proceda a la incoacción del oportuno expediente y, previos los trámites e informes legalmente preceptivos y dictamen de la Comisión Informativa, se eleve al Pleno la correspondiente propuesta de acuerdo, si lo solicitado fuera posible desde los puntos de vista jurídico y económico-financiero. Y ello debe ser así porque si, con carácter general, el Equipo de Gobierno municipal, para obtener la decisión del Pleno precisa, por imperativo legal, la incoación del oportuno expediente, por ser éste, y no otro documento, el que ha de someterse a dictamen de la Comisión Informativa (art. 91.1 R.O.F.), 
resultaría cuando menos paradójico que cualquier Grupo municipal pudiese obviar los trámites requeridos legalmente a través de la utilización generalizada de las proposiciones.

«Consiguientemente, por las razones expuestas, cobra excepcional importancia el que el asunto objeto de la proposición sea verdaderamente urgente, esto es, que la adopción del acuerdo sea apremiante o no pueda aplazarse. No obstante, existen asuntos que, aun cuando se acreditase la urgencia, el empleo de la proposición no tiene efectos inmediatos, por cuanto para poder adoptar acuerdos resolutivos sobre ellos se requiere, con carácter previo y preceptivo, informe del Secretario General, del Interventor General o de ambos, por referirse a materias para las que se exige mayoría especial (art. 47 L.R.B.R.L. en relación con el 54 T.R.R.L. y 173.1 R.O.F.), o por implicar los mismos un gasto o el reconocimiento de una obligación (artículos 435 y 455 T.R.R.L.) o por utilizarse una forma de contratación que no es la normal establecida para ciertas clases de contratos (art. 20.1 del Reglamento de Contratación de las Corporaciones Locales — hoy nos referiríamos a la L.C.A.P.-) o bien por la necesaria aportación, con carácter previo, de documentos, como, por ejemplo, en materia de contratación los Pliegos de Condiciones técnicas y económico-administrativas o bien por requerirse inexcusablemente el cumplimiento de determinadas formalidades, como sucede, por ejemplo, en materia de concesiones sobre bienes de dominio público (art. 80 del Reglamento de Bienes); adoptar en estos casos acuerdos sobre el fondo y de carácter resolutivo, determinaría su invalidez.

«Por tanto, en todos estos casos — que por supuesto no son los únicos- si quiere el Pleno asumir los términos de la proposición, deberá limitarse a tomarla en consideración y remitirla al Area correspondiente para que se incorporen los informes y documentos preceptivos y, previo dictamen de la Comisión Informativa, sea, de nuevo, sometido al Pleno.

«Finalmente, respecto de los expedientes en que no se den las anteriores circunstancias — que serán los menos-, si la Corporación entiende que puede fundadamente adoptar acuerdos sin necesidad de conocer ningún otro dato, ni siquiera el informe del Jefe de la Dependencia, que ha de emitirse y en el que se contienen, además de otros extremos, las disposiciones legales aplicables, podría adoptarse acuerdo en los términos propuestos. No obstante, antes de adoptarse el acuerdo, cualquier Concejal puede pedir su retirada previamente a efectos de que se incorporen a la proposición documentos e informes, en cuyo caso, de prosperar esa petición, no se entrará en el fondo del asunto. Obviamente no será preciso proceder a su retirada si no se adopta acuerdo resolutivo y se limita el Pleno a tomarla en consideración y posterior estudio»».

«En este sentido, insisto, es en el que se manifiesta esta Secretaría en su informe referido de...Pero en el supuesto de que no fuera correcta esta interpretación...y si se entendiera que las proposiciones presentadas por todos y cada uno de los Grupos políticos municipales fueran aprobadas constituyendo actos finales de un procedimiento $\mathrm{y}$, en consecuencia, verdaderos actos administrativos (interpretación que, reitero, esta Secretaría considera incorrecta), el planteamiento en el caso que se estudia tendría que ser: primero, hay proposiciones aprobadas, cualquiera que sea el número de votos que las respalden, compatibles y complementarias entre sí; segundo, habría proposiciones incompatibles entre sí y ambas aprobadas; y, tercero hay 
proposiciones que caen fuera de la competencia del Pleno, por estar su contenido reservado estatutariamente al Consejo de Administración o a la Junta General de la Empresa.

«Respecto de las primeras, la función del Equipo de Gobierno sería llevarlas a su puro y debido cumplimiento, directamente si es posible, o mediante la formulación del correspondiente expediente, aprobación del contrato, convenio, etc.; es decir, a través de los actos de desarrollo necesarios.

«En relación con las segundas, corresponde al Alcalde (art. 41.25 del R.O.F.) ejecutar y hacer cumplir los acuerdos del Ayuntamiento. Como quiera que no podría ejecutar y hacer cumplir acuerdos contradictorios tendría necesidad de someterlos nuevamente al Pleno Corporativo para que este estableciera definitivamente su postura.

«Finalmente las que excedieran de la competencia municipal, por estar atribuidas a órganos de la Empresa, han de considerarse nulas, de acuerdo con el apartado a) del núm. 1 del art. 47 de la Ley de Procedimiento Administrativo (hoy sería el 62 de la L.R.J.P.A.C.).

«Entre las proposiciones presentadas y aprobadas (en el supuesto de que se entendiera válida su aprobación) las hay que previamente hubieran requerido informe de la Intervención o de la Secretaría. Tales acuerdos, nulos o anulables, no son de posible convalidación, ya que la emisión del informe a posteriori no produce la convalidación, si el informe es preceptivo (art. 53.5 L.P.A. - hoy el art. 67 L.R.J.P.A.C. no recoge esa causa inhabilitadora de la convalidación-). Así ocurre con los acuerdos de contenido económico, en orden a la condonación de deudas, por ejemplo, y con los de cambio de forma concreta de gestión, en los que es preceptivo el informe del Secretario (art. 54.1.b T.R.R.L.) por requerir quórum especial de mayoría absoluta (art. 47.3.f L.R.B.R.L.). En consecuencia, los acuerdos referidos al cambio de gestión indirecta - Empresa Mixta o de capital mixto- a gestión directa -Empresa de capital íntegramente municipal—, cuando el servicio está municipalizado en régimen de monopolio, precisan de informe de la secretaría, además de necesitar para la validez del acuerdo mayoría absoluta del número legal de concejales (es el caso de la propuesta $2 .^{\circ}$ de ......, aprobada con solo 26 votos — serían precisos 29 - y la $4 .^{\circ}$ de las de ... aprobada también supuestamente con el mismo número de votos).

«En cualquier caso, los acuerdos adoptados lo serán en sus concretos términos. A modo de ejemplo, la propuesta sexta de las presentadas por...con gran rigurosidad jurídico-formal, plantea una solicitud de ceses, lógicamente a quien tenga competencia para producirlos, y el acuerdo del Pleno es, lógicamente, sumarse a esa solicitud, no acordar los ceses, para lo que no tiene competencia.

«En consecuencia, las propuestas aprobadas, manteniendo este criterio, serían válidas excepto las que se hayan aprobado sin informes preceptivos, que no son ni siquiera convalidables (ya se ha dicho que hoy sí lo serían) y las precisadas de mayoría cualificada que, al no obtenerse, se deben entender como no adoptadas». 


\section{VALOR DE LOS DICTÁMENES EMITIDOS POR LAS COMISIONES INFORMATIVAS EN EXPEDIENTES EN LOS QUE SE HAN OMITIDO TRÁMITES ESENCIALES}

Mediante escrito fechado el día 3 de diciembre actual, recibido el día de hoy, el Concejal... me solicita informe «para determinar la validez o no de los dictámenes de la Comisión Informativa de Hacienda y Economía celebrada el día 24 de noviembre pasado y en concreto sobre los siguientes extremos:

1. ${ }^{\circ}$ Si desde el momento en que se convocan sesiones de las Comisiones Informativas deben estar expuestos los expedientes, y éstos deben estar completos, al menos en sus elementos esenciales.

2. Si tienen validez legal los dictámenes de las Comisiones Informativas en el caso de que se haya cumplido lo referido en el punto $1 .^{\circ}$, toda vez que no se les asignó en ningún caso a los expedientes el carácter de extraordinarios o urgentes.

3. Si los acuerdos del Pleno, relativos a los puntos del Orden del Día dictaminados previamente por las Comisiones Informativas que hayan incumplido el punto $1 .{ }^{\circ}$, son válidos o deben ser anulados».

De conformidad con lo interesado se emite informe en los términos siguientes:

1. En el escrito que se analiza, se afirma de forma general que varios de los expedientes que se conocieron en la Comisión Informativa de Hacienda y Economía celebrada el día 24 del mes pasado «no figuraban completos, concretándose, sin embargo, a continuación que el que figuraba en el punto 3.1 del Orden del Día «Proponiendo la modificación del vigente Presupuesto General del Ayuntamiento de Madrid, en los términos que figuran en el expediente», carecía del informe preceptivo del Interventor.

También de forma generalizada se requiere informe de la Secretaría «para determinar la validez o no de los dictámenes de la citada Comisión Informativa» con lo cual se hace un planteamiento general, no referible solamente al punto 3.1 del Orden del Día, que luego se concreta en los aspectos antes transcritos literalmente.

Por ello parece oportuno señalar que esta Secretaría no puede generalizar una opinión sobre la tramitación que hubieran seguido los expedientes que se sometieron a la Comisión Informativa en aquella sesión, o las carencias que pudieran tener los mismos, ya que ni los examinó en ese 
momento ni ahora conoce el estado que tuvieran entonces, ya que únicamente sabe, por lo que dice el Sr. Concejal, que el que figuraba al punto 3.1. no estaba debidamente tramitado al no haberse emitido el informe preceptivo del Interventor General. No obstante, realmente lo que se quiere saber, con un valor de generalidad, que luego podría aplicarse a los acuerdos adoptados por el Pleno referentes a los asuntos tratados por aquella Comisión Informativa es si el conocimiento por una de ellas de un expediente en el que no figuran trámites esenciales y concretamente informes preceptivos, pueden originar la adopción de un acuerdo por el Pleno viciado de nulidad o de, al menos, anulabilidad.

2. Centrada así la consulta que se formula a esta Secretaría parece obligado, antes de entrar en su fondo, determinar cuál es el carácter de las Comisiones Informativas y el valor jurídico de sus dictámenes, porque quizá este entendimiento apunte ya una vía de solución o de respuesta.

El art. 123 del R.O.F. atribuye a estos órganos funciones de estudio, informe o consulta, negándoles expresamente facultades o competencias resolutorias, lo que supone su encuadre normativo entre los denominados «órganos consultivos».

En un procedimiento esencialmente escrito, como el administrativo, es lógico que los informes y dictámenes de los órganos consultivos alcancen una especial relevancia en cuanto declaraciones de juicio emitida por órganos especialmente cualificados a los efectos de ilustrar la voluntad del órgano de decisión y proporcionarle los elementos de juicio necesarios para dictar una resolución con garantías de acierto.

Tanto es así que, incluso, como es lo general, cuando el dictamen no es preceptivo si la decisión se aparta de él, habrá de motivarse, en sucinta referencia de hechos y fundamentos de Derecho, conforme exige el art. 43.1 c) de la Ley de Procedimiento Administrativo (hoy sería el art. 54.1.c de la L.R.J.P.A.C.). Así lo tiene declarado la jurisprudencia y, concretamente la Sentencia de 6 de julio de 1969, dice:

«aunque los informes de los órganos consultivos de la Administración no vinculan a la misma, en una valoración discrecional primero y lógica después, tales informes merecen un determinado crédito de veracidad, dado el juicio de pericia o apreciación de conocimiento típicos sobre datos y circunstancias preexaminadas que comportan un obligado alcance y máxime cuando se han producido con unanimidad»

No parece que pueda existir duda, pues, de que los órganos consultivos están adornados por el conocimiento especial técnico de las materias que se les someten, que les califica para emitir juicio de pericia, como expre- 
samente señala la Sentencia referida sobre el proyecto de resolución que figura en el expediente necesariamente instruido al efecto.

Pero la integración de las Comisiones Informativas en la esfera local, exclusivamente formadas por miembros de la Corporación (art. 123 R.O.F.), niega este carácter técnico o pericial a sus dictámenes, ilustración que habrá de buscarse en otros informes incorporados al expediente (art. 175 R.O.F. y art. 54 T.R.R.L.).

Además, el hecho de que la composición de las Comisiones Informativas se acomode a la proporcionalidad existente entre los distintos Grupos políticos representados en la Corporación (art. 125.b R.O.F.) otorga a estos órganos un especial carácter que los aleja del propio del órgano consultivo tal como lo concibe la doctrina y la jurisprudencia.

Las Comisiones Informativas han de entenderse como órganos a los que corresponde preparar y estudiar previamente los asuntos que, por su importancia, han de ser sometidos a decisión del Pleno, de manera que hagan más ágiles las deliberaciones de éste. Sus valoraciones, por tanto, más que opiniones técnicas deben considerarse como apreciaciones de oportunidad o de conveniencia política.

Abona este razonamiento el que las Comisiones Informativas no tengan la condición de órganos necesarios en el gobierno y administración del Municipio, de manera que por ser complementarios de aquellos otros, su creación y, en su caso, regulación se deja libremente a la voluntad de los Ayuntamientos mediante su Reglamento orgánico (art. 20.1 L.R.B.R.L.) aunque luego el R.O.F. posibilite su creación, composición concreta y regulación mediante simple acuerdo del Pleno Corporativo.

De cualquier manera, no puede desconocerse que, según afirma este mismo Reglamento, las Comisiones Informativas no tienen atribuciones resolutorias y sus dictámenes no son vinculantes para la Corporación (art. 126.1 R.O.F.).

3. Como se ha puesto de relieve antes, los dictámenes de cualquier órgano consultivo tienen la consideración de declaraciones de juicio, ilustrativas del órgano decisor $\mathrm{y}$, por tanto, constituyen actos de trámite no resolutorios, conforme advierte el art. 123 R.O.F. en referencia expresa a las Comisiones Informativas.

En la esfera local esos dictámenes son preceptivos (a falta de Reglamento orgánico que dispusiere otra cosa) de manera que su omisión invalidaría el acuerdo que se adoptase, excepto en los acuerdos de urgencia a 
que se refiere el art. 97.2 y 3 en relación respectivamente con los arts. 82.3 y 91.4 del R.O.F.

Por otro lado los dictámenes no tienen carácter vinculante y, por tanto, no obligan ni fuerzan el acto resolutorio, que vendrá determinado por la voluntad mayoritaria del Pleno (art. 126.1 R.O.F.).

Cuestión importante es la de determinar los límites en que ha de producirse el dictamen o, lo que es lo mismo, qué margen se impone a la actuación de las Comisiones Informativas. La respuesta viene dada en el mismo Reglamento cuando en su art. 172, dice:

«Los informes administrativos, jurídicos o técnicos y los dictámenes de las Juntas y Comisiones se redactarán con sujeción a las disposiciones especiales que les sean aplicables y se ceñirán a las cuestiones señaladas en el Decreto o acuerdo que los haya motivado»

No cabe duda, pues, como parece lógico, de que el dictamen debe concretarse a la cuestión propuesta en el expediente, sin que quepa su emisión sobre aspectos o materias que no se relaciones directamente en el acuerdo en proyecto o propuesta que figure en el expediente.

En cuanto a la forma de manifestarse el dictamen, el art. 136.2 R.O.F., establece:

«El dictamen de a Comisión podrá limitarse a mostrar su conformidad con la propuesta que le sea sometida por los servicios administrativos competentes o bien formular una alternativa».

Este precepto, de especial importancia, supone una innovación e incluso una alteración del sistema normal de votación previsto en los arts. 98 y 109.1 del R.O.F. respecto del Pleno, a los que remiten los arts. 137.2.h) y 138 del Texto reglamentario.

Es decir, que conforme al artículo transcrito no cabe rechazar sin más la propuesta que figure en el expediente, sino que necesariamente, si no se conforma aquélla deberá formularse una alternativa; o, lo que es lo mismo, no caben actitudes negativas: el dictamen ha de considerarse siempre en sentido «constructivo».

La propuesta que formule la Comisión, según declara el art. citado, es alternativa a la que figura en el expediente. Supone ello que esta última no queda desprovista de valor sino que deberá ofrecerse al Pleno juntamente con la emanada de la Comisión para su debate y decisión. La redacción de la disposición no admite otra interpretación, pues «alterna- 
tiva» supone según la Real Academia de la Lengua «opción entre dos cosas».

Y ello además parece lógico porque la propuesta que figura en el expediente ha sido configurada tras los estudios e informes unidos al mismo, que justifican su racionalidad jurídica, según previenen los arts. 172 a 175 R.O.F., y la propia naturaleza del expediente administrativo demanda (art. 164 R.O.F.), máxime si éste se ha iniciado de oficio por necesidades del servicio público.

La propuesta contenida en el expediente supone el ejercicio de la competencia de «gobierno y administración municipales» que el art. 21.1 a de la L.R.B.R.L. atribuye al Alcalde (y por su delegación a los Concejales que la tengan por razón de la materia), competencia que no puede desconocerse so pena de chocar con aquel reconocimiento legal de ella. Por ello la propuesta originaria emanada de quien ha asumido legítimamente por voluntad popular el gobierno municipal no puede sustraerse al conocimiento del Pleno a quien compete, en todo caso, adoptar la decisión procedente a la vista de la propuesta del expediente y de la alternativa de la Comisión. Únicamente en el caso de que el Alcalde o el Concejal delegado firmantes de la propuesta asumieran la formulada por la Comisión, ésta sería la única objeto de consideración y debate por el Pleno.

4. Desde otro punto de vista, la omisión de un trámite esencial en un procedimiento puede originar la nulidad o, al menos, la anulabilidad de un acto administrativo, mientras que cualquier otra infracción aislada no produce efectos tan radicales de entender viciado de nulidad el acto administrativo.

La dificultad, quizá, esté en determinar qué se entiende por trámite esencial en un expediente, dificultad que quiere resolver la jurisprudencia considerando como tales aquellos sin los cuales un procedimiento concreto es identificable (SS.T.S. de 10 de mayo de 1969 y 30 de septiembre de 1970). Por ejemplo, en materia de expropiación forzosa tiene este carácter el incumplimiento de los requisitos sustanciales de declaración de utilidad pública o interés social, la necesidad de ocupación o el previo pago o depósito.

Si nos referimos de manera concreta a los informes habrá que distinguir los que tienen carácter preceptivo de los que solo son facultativos, según que venga o no exigida su emisión por las normas aplicables en cada caso concreto. La omisión de un informe preceptivo constituye un vicio de nulidad que no puede ser convalidado posteriormente, al haberse dictado el 
acto, según advierte el art. 53.5 de la L.P.A. (reiteramos una vez más la supresión del impedimento en la L.R.J.P.A.C.).

En la situación que estudiamos no puede tampoco desconocerse que la emisión de informe cualquiera que sea su naturaleza se hace por un órgano que se sitúa dentro de lo que se denomina Administración consultiva en la que también se encuadran las Comisiones Informativas de los Ayuntamiento. Por ello es lícito preguntarse si la emisión de dictamen por la Comisión Informativa viene condicionada necesariamente a que se hayan emitido otros informes, preceptivos o no, ya que podría pensarse - máxime dada la ausencia de valoración pericial o técnica que hamos atribuido a los dictámenes de as Comisiones Informativas- si éstos pueden evacuarse sin otros condicionamientos que el conocer la propuesta concreta que quiere someterse al Ayuntamiento Pleno, aunque esta duda no tiene mayor relieve en el supuesto contemplado puesto que la Comisión de Hacienda y Economía celebrada el día 24 de noviembre se consideró capacitada para emitir el informe o dictamen.

Pero aun cuando no fuera así, parece que existen otras apreciaciones que desvían la cuestión hacia el Pleno corporativo. En efecto, la falta de informe preceptivo puede invalidar la decisión del Pleno, cuando se haya omitido ese trámite esencial o se hubiere realizado en momento procesal inadecuado, ya que la falta de ese informe en el momento de someterse el expediente al dictamen de la Comisión Informativa no invalida el acuerdo posterior de la Corporación si cuando el expediente llega a ella el informe se ha producido.

El incumplimiento de un trámite esencial en un procedimiento $-\mathrm{y}$ este carácter lo tiene el informe preceptivo- puede determinar la nulidad de un acto adoptado por el Pleno de la Corporación, ya que su ausencia, aparte de vulnerar la exigencia legal al prescindir de un requisito necesario, afecta a la formación de la voluntad del órgano resolutorio, que ha carecido de la ilustración o información debida para que aquélla se forme adecuadamente, pero no ocurre lo mismo en relación con la Comisión Informativa cuya finalidad no es sino la de preparar los asuntos que vayan al Pleno siendo sus actos, en términos generales actos de trámite. Puede la Comisión, evidentemente, detectar la carencia del informe y requerir que se aporte al expediente antes de la convocatoria del Pleno, pero su carencia no invalida su propio dictamen.

Tiene apoyo esta afirmación en la misma Ley Básica de Régimen Local, cuando en su art. 46.2.b) señala que «la documentación íntegra de los asuntos incluidos en el orden del día que deba servir de base al debate 
y en su caso, votación, deberá figurar a disposición de los Concejales, desde el mismo día de la convocatoria en la Secretaría General de la Corporación» - precepto que luego reitera el art. 84 del R.O.F.- luego no es exigible con anterioridad.

5. En conclusión y en razón de las distintas cuestiones planteadas en la consulta que se nos ha formulado y a lo expuesto anteriormente, puede afirmarse:

a) Las Comisiones Informativas son órganos que se sitúan dentro de lo que la doctrina denomina Administración consultiva, si bien sus dictámenes en ningún caso, a diferencia de lo que pueda suceder en otras Administraciones públicas, tienen carácter vinculante.

b) Las Comisiones Informativas, pese a esa consideración anterior, presentan un carácter marcadamente político o de auxilio al Pleno, ya que carecen de la nota de preparación técnica o pericial que configura a los órganos consultivos.

c) La ausencia de trámites esenciales, sustanciales o de otro tipo en un expediente administrativo en el momento de emitirse el dictamen por la Comisión informativa no invalida por sí misma el acuerdo que pueda adoptarse posteriormente por el Pleno de la Corporación.

d) El incumplimiento de un trámite esencial, como puede serlo el informe preceptivo, puede invalidar el acuerdo adoptado por el Pleno si tal ausencia se advirtiera en el expediente en el momento en que el mismo se puso a disposición de los Concejales, al incluir el asunto en el Orden del Día del Pleno, en cuanto que éstos no tuvieron la información necesaria con la antelación suficiente, pudiéndose ver afectada la formación de la voluntad del órgano colegiado.

e) La falta de un informe preceptivo, por sí solo, invalidaría el acto administrativo dictado por el órgano competente, por haber prescindido de un trámite necesario en el procedimiento.

f) Cualquier otra infracción procedimental, aunque sea importante, no produce efectos de nulidad, aun cuando podría servir de fundamento en apoyo de cualquier pretensión anulatoria en vía de recurso. 